\title{
Penyuluhan Strategi Komunikasi Pemasaran Pada Usaha Kecil Dan Menengah Di Kelurahan Cipondoh Makmur Tangerang
}

\author{
Wendi Usino $^{1}$, Dewi Murtiningsih ${ }^{2 \bowtie}$, Feby Lukito Wibowo ${ }^{3}$ \\ Fakultas Teknologi Informasi, Universitas Budi Luhur, Indonesia ${ }^{1}$ \\ Fakultas Ekonomi dan Bisnis, Universitas Budi Luhur, Indonesia ${ }^{2,3}$ \\ E-mail: wendi.usino@budiluhur.ac.id ${ }^{1}$ dewi.murtiningsih@ budiluhur.ac.id $^{2}$ feby.luckito@ budiluhur.ac.id $^{3}$
}

\begin{abstract}
Abstrak
Usaha skala mikro seringkali terkendala berbagai permasalahan terutama dibidang pemasaran. Kegiatan promosi yang dilakukan oleh UMKM masih terkendala biaya sehingga hanya beberapa unsur komunikasi dalam pemasaran terpadu yang dapat diterapka UMKM yaitu: iklan, publisitas, promosi penjualan dan pemasaran langsung. Oleh karenanya perlu ada role model perumusan strategi komunikasi pemasaran yang diperlukan bagi usaha skala mikro. Adapun tujuan yang ingin di capai dalam kegiatan ini adalah meningkatkan kemampuan dan pengetahuan usaha kecil dan menengah melalui strategi komunikasi pemasaran untuk memasarkan produk yang lebih luas sehingga penjualan bisa meningkat; meningkatkan kemampuan pelaku usaha kecil dan menengah dalam mengembangkan usahanya melalui strategi komunikasi pemasaran. Manfaat langsung yang diperoleh dari kegiatan pengabdian masyarakat ini adalah diharapkan dapat membantu pihak usaha kecil dan menengah mendapatkan tambahan wawasan dan pengetahuan terkait pemanfaatan strategi komunikasi pemasaran untuk mempromosikan produk usahanya sehingga bisa meningkatkan penjualan; diharapkan dapat memberikan pemahaman dan wawasan dalam pemahaman terkait strategi pemasaran yaitu strategi komunikasi pemasaran pada pelaku usaha kecil dan menengah di Kelurahan Cipondoh Makmur Kota Tangerang.
\end{abstract}

Kata kunci: strategi komunikai pemasaran, usaha kecil dan menengah

\section{Abstract}

Micro-scale businesses are often constrained by various problems, especially in the field of marketing. Promotional activities carried out by MSMEs are still constrained by costs so that only a few elements of communication in integrated marketing can be applied by MSMEs, namely: advertising, publicity, sales promotion and direct marketing. Therefore, there needs to be a role model for formulating marketing communication strategies needed for micro-scale businesses. The objectives to be achieved in this activity are: Improving the ability and knowledge of small and medium enterprises through marketing communication strategies to market products more broadly so that sales can increase; Improving the ability of small and medium enterprises in developing their business through marketing communication strategies. The direct benefits obtained from this community service activity are as follows: It is hoped that it can help small and medium-sized businesses gain additional insight and knowledge regarding the use of marketing communication strategies to promote their business products so as to increase sales; It is hoped that it can provide understanding and insight in understanding marketing strategies, namely marketing communication strategies for small and medium business actors in Cipondoh Makmur Village, Tangerang City.

Keywords: Marketing Communication Strategy, Small and Medium Enterprises

Copyright (c) 2021 Wendi Usino, Dewi Murtiningsih, Feby Lukito Wibowo

$\triangle$ Corresponding author

Address : Universitas Budi Luhur

Email : dewi.murtiningsih@budiluhur.ac.id

DOI : https://doi.org/10.31004/abdidas.v2i4.361

ISSN 2721- 9224 (Media Cetak)

ISSN 2721- 9216 (Media Online) 
843 Penyuluhan Strategi Komunikasi Pemasaran Pada Usaha Kecil Dan Menengah Di Kelurahan Cipondoh Makmur Tangerang - Wendi Usino, Dewi Murtiningsih, Feby Lukito Wibowo

DOI: https://doi.org/10.31004/abdidas.v2i4.361

\section{PENDAHULUAN}

Menurut UU No. 20/2008, yang dimaksud usaha mikro adalah usaha produktif milik orang perorangan dan/ atau badan usaha perorangan yang memenuhi kriteria Usaha Mikro sebagaimana diatur dalam Undangundang ini. Usaha kecil adalah usaha ekonomi produktif yang berdiri sendiri, yang dilakukan oleh orang perorangan atau badan usaha yang bukan merupakan anak perusahaan atau bukan cabang perusahaan yang dimiliki, dikuasai, atau menjadi bagian baik langsung maupun tidak langsung dari usaha menengah atau usaha besar. Usaha menengah adalah usaha ekonomi produktif yang berdiri sendiri, yang dilakukan oleh orang perseorangan atau badan usaha yang bukan merupakan anak perusahaan atau cabang perusahaan yang dimiliki, dikuasai, atau menjadi bagian baik langsung maupun tidak langsung dengan usaha kecil atau usaha besar dengan jumlah kekayaan bersih atau hasil penjualan tahunan (UURI, 2008).

Usaha skala mikro seringkali terkendala berbagai permasalahan terutama dibidang pemasaran, apalagi dalam kondisi harus bersaing dengan perusahaan skala menengah ataupun indusri skala besar lainnya. O'broin (2013), menyatakan bahwa diperkirakan sekitar $70 \%$ bisnis kecil mengalami kebangkrutan setelah 5 tahun berjalan. Persentase yang sedemikian besar disebabkan oleh strategi komunikasi pemasaran yang buruk.

SMME Desk of Durban Chamber of Commerece (2009), menyatakan bahwa 90\% bisnis skala mikro tidak bisa bertahan dalam lima tahun pertama bukan karena produknya tetapi karena tidak mampu membangun tempat dalam pasar. Van Scheers dan Radipere (2008), menambahkan bahwa komunikasi pemasaran adalah bantuan utama bagi usaha skala mikro untuk membedakan diri dari para pesaing. Kegiatan promosi yang dilakukan oleh UMKM masih terkendala biaya sehingga hanya beberapa unsur komunikasi dalam pemasaran terpadu yang dapat diterapkan UMKM yaitu: iklan, publisitas, promosi penjualan dan pemasaran langsung. Dengan dana terbatas, UMKM dapat menggunakan kegiatan promosi antara lain penyebaran brosur, pemasangan banner, pemberian diskon atau contoh prosuk secara gratis serta pemasaran online menggunakan internet (Chrismardani, 2014).

Secara umum, ketika mengamati bentukbentuk komunikasi pemasaran yang dilakukan perusahaan berskala kecil dan menengah, keterbatasan dana tetap terlihat. Perusahaanperusahaan itu tetap saja tidak dapat secara maksimal melakukan komunikasi pemasaran akibat keterbatasan dana. Hal ini membuat mereka cenderung memanfaatkan hal-hal yang mampu mereka lakukan seperti pemberian 
844 Penyuluhan Strategi Komunikasi Pemasaran Pada Usaha Kecil Dan Menengah Di Kelurahan Cipondoh Makmur Tangerang - Wendi Usino, Dewi Murtiningsih, Feby Lukito Wibowo

DOI: https://doi.org/10.31004/abdidas.v2i4.361

diskon, iklan baris, ataupun undangan publikasi melalui radio (Isnaini, 2010). Serupa dengan Etaswara dalam Hidayat (2011), menyatakan bahwa pemasaran era informasi adalah komunikasi dan komunikasi adalah pemasaran dimana keduanya tidak dapat dipisahkan. Oleh karenanya perlu ada role model perumusan strategi komunikasi pemasaran yang diperlukan bagi usaha skala mikro untuk membantu pengembangan bagi usaha skala mikro tersebut (Hidayanti, 2018).

Kondisi objek kajian adalah pelaku usaha kecil dan menengah di kelurahan Cipondoh Makmur Kota Tangerang. Dimana pada saat sekarang ini, pandemic Covid-19 terjadi sebagian pelaku usaha kecil dan menengah di Kelurahan Cipondoh Makmur mengalami penurunan tingkat penjualan. Serta pelaku usaha kecil dan menengah saat ini hanya mengandalkan pemesanan lokal dan belum memiliki rencana dan pemahaman pemasaran secara komprehensif dan efektif. Dan kurangnya pengetahuan dalam strategi komunikasi pemasaran, menginggat konten pemasaran baik offline maupun online sangat membantu untuk mempromosikan produk agar menjangkau daerah yang lebih luas dan pasar sasaran yang sesuai. Kegiatan. Diharapkan dengan sosialisasi dalam pengabdian masyarakat ini dapat menambah pengetahuan dan wawasan bagi pelaku usaha kecil dan menengah di Kelurahan Cipondoh Makmur Kota Tangerang.

Adapun tujuan yang ingin di capai dalam kegiatan ini adalah meningkatkan kemampuan dan pengetahuan usaha kecil dan menengah melalui strategi komunikasi pemasaran untuk memasarkan produk yang lebih luas sehingga penjualan bisa meningkat; meningkatkan kemampuan pelaku usaha kecil dan menengah dalam mengembangkan usahanya melalui strategi komunikasi pemasaran.

Manfaat langsung yang diperoleh dari kegiatan pengabdian masyarakat ini adalah sebagai berikut: a). bagi pelaksana kegiatan: dapat memperkenalkan program dan kegiatankegiatan yang dilakukan oleh Universitas Budi Luhur sekaligus tentang eksistensi dari lembaga ini kepada masyarakat luas; b). bagi segi kebijakan: diharapakan dapat membantu pihak usaha kecil dan menengah mendapatkan tambahan wawasan dan pengetahuan terkait pemanfaatan strategi komunikasi pemasaran untuk mempromosikan produk usahanya sehingga bisa meningkatkan penjualan; c). bagi masyarakat: diharapkan dapat memberikan pemahaman dan wawasan dalam pemahaman terkait strategi pemasaran yaitu strategi komunikasi pemasaran pada pelaku usaha kecil dan menengah di Kelurahan Cipondoh Makmur Kota Tangerang. 


\section{METODE}

Untuk mencapai tujuan pengabdian, kegiatan pengabdian kepada masyarakat ini dilaksanakan dengan metode penyuluhan. Dengan metode ini kegiatan dilakukan dalam bentuk penyampaian materi dan diskusi. Rancangan pelaksanaan kegiatan pengabdian kepada masyarakat ini adalah sebagai berikut : 1). kegiatan penyuluhan diawali dengan memperkenalkan Program Fakuktas dan Program Studi. 2). Penyuluhan: memberikan pengetahuan tentang berbagi aplikasi/ perangkat lunak yang dapat digunakan dalam proses pemasaran produk secara digital. 3). Pada metode penjelasan, pembicara akan menyampaikan materi terkait dan membuat tampilan visual berupa slide power point. 4). Narasumber dalam menyampaikan penjelasan juga memasukkan unsur sharing atau berbagi ilmu dalam strategi komunikasi pemasaran dalam promosi bisnis. 5). Metode yang digunakan pada program kegiatan ini diharapkan dapat memberikan kemudahan kepada peserta kegiatan pengabdian kepada masyarakat. 6). Dalam kegiatan ini metode yang digunakan adalah metode penjelasan, sharing, tanya jawab dan diskusi.

\section{HASIL DAN PEMBAHASAN}

Hasil dari pengabdian masyarakat pada UMKM di Lingkungan RW 003 Kelurahan Cipondoh Makmur yaitu:

1. Pengabdian kepada masyarakat yang dilaksanakan pada Hari Jumat Tanggal 11 Juni 2021 dihadiri oleh Bapak Rektor Universitas Budi Luhur, Bapak Camat dengan yang mewakilinya yaitu Bapak sekretaris Camat yang sekaligus merangkap sebagai bapak Lurah di Cipondoh Makmur, Bapak RW 003 sekaligus sebagai ketua UMKM, bapak Sekretaris Pengurus UMKM RW 003, dan Pelaku UMKM di Cipondoh Makmur.

2. Adanya sambutan dari bapak Haji Taufik, selaku Ketua RW 000 Kelurahan Cipondoh yang merespon dan menyambut baik adanya kegiatan-kegiatan penyuluhan untuk pelaku UMKM dalam rangka meningkatkan pengetahuan dan pemahaman pelaku UMKM di Cipondoh Makmur.

3. Adanya masukan dari bapak Sekretaris Camat sekaligus sebgi bpk Lurah di Cipondoh makmur terkait dengan adanya pengabdian kepada masyarakat yang dilaksanakan secara berkelanjutan dan diusahakan jangan hanya sehari, karena menurut bapak Sekretaris Camat tersebut PKM merupakan kegiatan yang bagus. 
846 Penyuluhan Strategi Komunikasi Pemasaran Pada Usaha Kecil Dan Menengah Di Kelurahan Cipondoh Makmur Tangerang - Wendi Usino, Dewi Murtiningsih, Feby Lukito Wibowo

DOI: https://doi.org/10.31004/abdidas.v2i4.361

4. UMKM di Kelurahan Cipondoh Makmur RW 003 kebanyakan bergerak dalam produk makanan ringan dan pakaian.

Berikut adalah foto-foto pelaksanaan Pengabdian Kepada Masyarakat (PKM) di UMKM Lingkungan RW 0073Kelurahan Cipondoh Makmur. Foto berikut berisi kegiatan-kegiatan pengabdian kepada masyarakat semester genap 2020/2021 yang dilaksanakan secara luring maupun daring atau online dengan link google meet: https://meet.google.com/pdf-gwcn-xfu.

Walaupun pelaksanaan dilakukan secara online juga, tetapi tidak mengurangi semangat dari peserta pengabdian kepada masyarakat. Terbukti dengan partisipasi pelaku UMKM di RW 003 Kelurahan Cipondoh yang hadir.

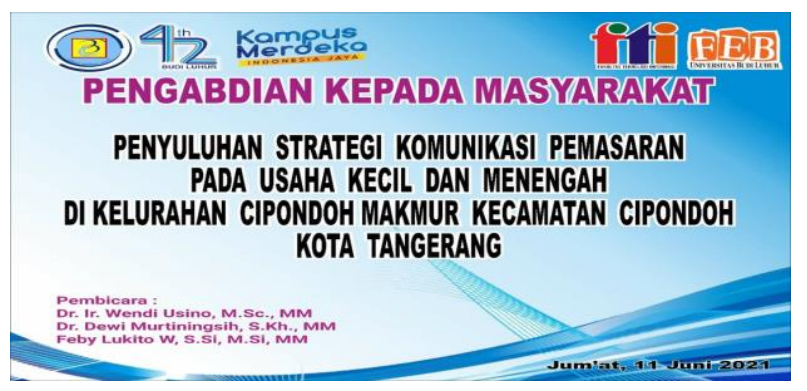

Gambar 1. Backdrop Kegiatan

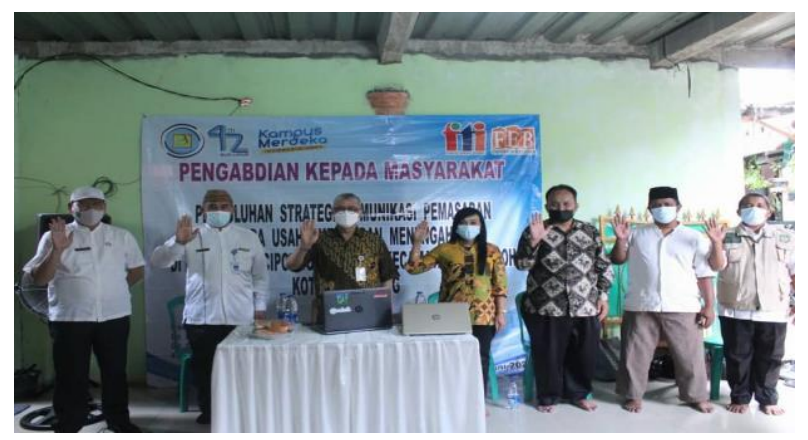

Gambar 2. Foto Bersama
Gambar 1. Adalah backdrop kegiatan PKM Genap 2021, sedangkan Gambar 2. diatas merupakan sambutan-sambutan pada acara pembukaan pengabdian kepada masyarakat. Diantaranya yang memberikan sambutan adalah bapak Rektor universitas Budi Luhur (Dr. Ir. Wendi Usino, M.Sc., MM), Bapak Sekretaris Camat sekaligus sebagai bapak Lurah Cipondoh Makmur (H. Malkan Al Masdo), BapakSekretaris Lurah Cipondoh Makmur (Nawami, S.Ip), dan Bapak Ketua RW 003 sekaligus sebagai keua UMKM Kelurahan Cipondoh (Bapak Haji Taufik).

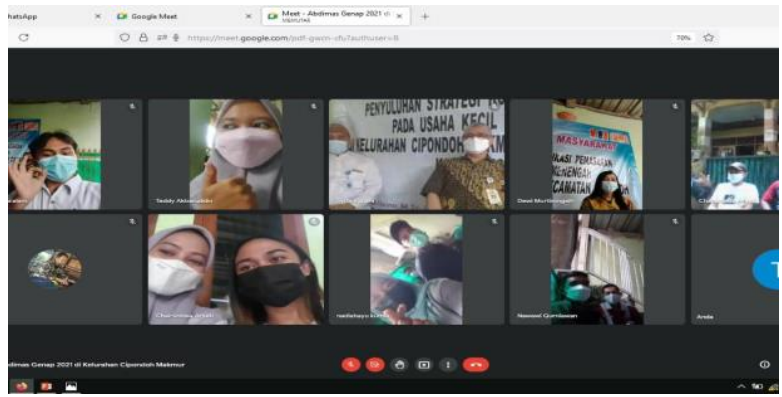

Gambar 3. Foto Tim dan Peserta Kegiatan

Pada Gambar 3 diatas adalah terdiri dari tim pelaksana pengabdian kepada masyarakat, asisten pelaksanan pengabdian kepada masyarakat, Sekretaris Camat yang sekaligus menjadi Lurah di Kelurahan Cipondoh Makmur, Pejabat Kelurahan Cipondoh Makmur, dan pelaku UMKM di RW 003 Kelurahan Cipondoh Makmur. 


\section{SIMPULAN}

Kesimpulan dari kegiatan pengabdian ini yaitu mampu meningkatkan kemampuan dan pengetahuan usaha kecil dan menengah melalui strategi komunikasi pemasaran untuk memasarkan produk yang lebih luas sehingga penjualan bisa meningkat serta meningkatkan kemampuan pelaku usaha kecil dan menengah dalam mengembangkan usahanya melalui strategi komunikasi pemasaran yang dilakukan melalui paparan materi PPT secara online serta tanya jawab; Mengenal lebih jauh Universitas Budi Luhur kepada warga di lingkungan Universitas Budi Luhur yang dilakukan dengan mempresentasikan Fakultas dan ProdiProdi yang terdapat di Universitas Budi Luhur melaui meet online.

Saran dari kegiatan pengabdian kepada masyarakat di lingkungan RW 003 Kelurahan Cipondoh Makmur yaitu: Perlu dilakukan pengabdian kepada masyarakat secara berkelanjutan terkait dengan adanya pelatihan atau aplikasi untuk memasarkan produk yang dihasilkan oleh wirausaha atau entrepreuner yang ada di UMKM Kelurahan Cipondoh Makmur.

\section{UCAPAN TERIMA KASIH}

Kami mengucapkan terima kasih kepada bapak Rektor Universitas Budi Luhur, Universitas Budi Luhur, Kelurahan Cipondoh Makmur, bapak sekretaris kecamatan serta
Pengurus RW, RT dan pengurus UMKM di Cipondoh Makmur.

\section{DAFTAR PUSTAKA}

Chrismardani, Yustina. (2014). Komunikasi Pemasaran Terpadu: Implementasi untuk UMKM. Jurnal NeO-Bis 8(2): 179-189.

Hidayat, Rahmad, Issa Dyah dan Romadhani, Sari. (2011). Pengembangan Strategi Komunikasi Pemasaran Industri Kecil Menengah (IKM). Journal of Strategic Communication 1(2): 205-221.

Hidayanti, Dwi Ratna. 2016. Strategi Komunikasi Pemasaran Usaha Skala Mikro (Mikro Enterprize) KUB Bajrah Gunah Klampis Bangkalan Pada Produk Terasi, Petis Dan Krupuk Ikan. Agriekonomika. Volume 5, Nomor 1. ISSN 2301-9948. eISSN 2407-6260.

Isnaini, Santi. (2010). Implementasi Komunikasi Pemasaran Terpadu sebagai Penyampai Pesan Promosi Usaha Kecil Menengah (UKM) di Indonesia. Jurnal Masyarakat Kebudayaan Dan Politik. 22(4): 324-332 .

O’broin, Ruadhiri. (2013). The Application of Integrated Marketing Communication by Micro Business in The Republic of Ireland. Dissertation. Business Administration of Dublin School.

Undang-Undang Republik Indonesia Nomor 20 Tahun 2008 Tentang Usaha Mikro, Kecil, dan Menengah.

Van Scheers, L \& Radipere, S. (2008). Gathering Perceptions of Soweto Small Business Owners on Advertising in Black Townships in South Africa. Journal of Global Business Advancement 1(4): 445-458. 